\title{
JUVENTUDE, FORMAÇÃO E TRABALHO: APROXIMANDO AS TEORIAS DE INSERÇÃO PROFISSIONAL E SCHOOL-TO-WORK
}

\author{
Jhony Pereira Moraes ${ }^{1,2}$ \\ SidineI RochA-DE-Oliveira ${ }^{3}$
}

\begin{abstract}
RESUMO: Este ensaio apresenta e discute as teorias de inserção profissional francesa e school-to-work. A discussão embasa a exploração dos aspectos de convergência das teorias, buscando ampliar o debate no Brasil, de modo a contemplar as particularidades do país. Em síntese, quatro pontos se destacaram: as reconfigurações do processo de inserção decorrentes das transformações estruturais do Ensino Superior brasileiro; a relação entre o ingresso de diferentes grupos étnicos e econômicos juvenis no Ensino Superior e os impasses ou avanços nas condições laborais; o risco do rebaixamento dos diplomas como consequência da ampliação do número de diplomados e a possível estratificação sócio-ocupacional; e a centralidade das instituições de educação superior na vida laboral dos jovens.

Palavras-chave: Inserção profissional. School-to-work. Juventude. Mercado de trabalho.

\section{YOUTH, TRAINING AND WORK: APPROACHING THE THEORIES OF PROFESSIONAL INSERTION AND SCHOOL-TO-WORK}

\begin{abstract}
This essay presents and discusses theories of French professional insertion and school-to-work. The discussion supports the exploration of the convergence aspects of the theories, seeking to broaden the debate in Brazil, in order to contemplate the particularities of the country. In summary, four points stand out: the reconfigurations of the insertion process resulting from the structural transformations of Brazilian Higher Education; the relationship between the entry of different youth ethnic and economic groups in Higher Education and the impasses or advances in working conditions; the risk of lowering diplomas as a consequence of the increase in the number of graduates and the possible sociooccupational stratification; and the centrality of Higher Education institutions in young people's working life.
\end{abstract}

Keywords: Professional insertion. School-to-work. Youth. Labor market.

Este texto é fruto da pesquisa "Inserção profissional e mobilidade social dos egressos dos Cursos de Administração no Brasil" realizada com apoio do Conselho Nacional de Desenvolvimento Científico e Tecnológico.

1.Universidade Federal do Rio Grande do Sul - Programa de Pós-Graduação em Administração - Porto Alegre (RS), Brasil. E-mail: jhonymoraes@hotmail.com.br

2.Faculdade de Desenvolvimento do Rio Grande do Sul - Escola de Ciências Sociais Aplicadas, Educação, Artes e Humanidades Porto Alegre (RS), Brasil.

3.Universidade Federal do Rio Grande do Sul - Programa de Pós-Graduação em Administração - Porto Alegre (RS), Brasil. E-mail: sroliveira@ea.ufrgs.br

Editor de Seção: Carmen Sylvia Vidigal Moraes 


\title{
JUVENTUD, FORMACIÓN Y TRABAJO: UNIENDO LAS TEORÍAS DE LA INSERCIÓN PROFESIONAL Y SCHOOL-TO-WORK
}

\begin{abstract}
RESUMEN: Este ensayo presenta y discute las teorías de la inserción profesional francesa y de la escuela al trabajo. La discusión apoya la exploración de los aspectos de convergencia de las teorías, buscando ampliar el debate en Brasil, para contemplar las particularidades del país. En resumen, se destacaron cuatro puntos: las reconfiguraciones del proceso de inserción producto de las transformaciones estructurales de la Educación Superior brasileña; la relación entre el ingreso de diferentes grupos étnicos y económicos juveniles a la Educación Superior y los estancamientos o avances en las condiciones laborales; el riesgo de rebajar los títulos como consecuencia del aumento del número de titulados y la posible estratificación sociolaboral; y la centralidad de las instituciones de educación superior en la vida laboral de los jóvenes.
\end{abstract}

Palabras-clave: Inserción profesional. School-to-work. Juventud. Mercado de trabajo.

\section{Introdução}

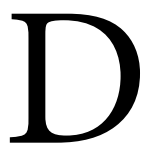

esde a década de 1990, transformações de magnitudes distintas vêm ocorrendo no mercado de trabalho (inovações tecnológicas, produção enxuta, internacionalização e desterritorialização) e no Ensino

Superior. As transformações sociais na esfera laboral influenciaram as formas de contratos estabelecidas entre as empresas e os trabalhadores (p. ex., os contratos temporários e aqueles intermediados por terceiros) e o incentivo à multifuncionalidade do trabalhador. Em paralelo, nota-se o crescimento e a diversidade das vagas no Ensino Superior, levando a uma significativa ampliação da qualificação da força de trabalho (INEP, 2019; VOLKMER MARTINS; ROCHA-DE-OLIVEIRA, 2017a; 2017b). Nesse contexto, a entrada dos jovens egressos dos cursos de graduação na esfera do trabalho, que, no século passado, ocorria de modo quase automático, tem se tornado um momento de incertezas, em que os efeitos das mudanças nos contratos de trabalho ganham uma dimensão ainda maior (GUIMARÃES, 2008; SANTOS, 2013).

Volkmer Martins e Rocha-de-Oliveira (2017b) salientam que as transformações que ocorreram no emprego, como a reorganização das normas de trabalho, impelem trajetórias cada vez mais segmentadas. Graças a isso, o trabalho precário tem atingido os mais jovens e se prolongado no tempo, aumentando o desemprego juvenil, embora haja acesso crescente da população ao nível superior (VOLKMER MARTINS; OLIVEIRA; ROCHA- DE-OLIVEIRA, 2017). Assim, torna-se necessário que se ampliem os estudos com foco no processo de inserção profissional de egressos da educação superior, considerando o crescimento desse grupo, que passa de $4 \%$ para $15 \%$ da população em menos de duas décadas (OCDE, 2018).

Portanto, para contextualizar esse campo, salienta-se que a inserção profissional assume duas correntes de pensamento: a anglo-saxônica e a francesa, com estudos que remontam aos anos 1970. Os aspectos que motivaram o olhar para esse campo nos países europeus podem ser sintetizados no prolongamento do tempo de estudo e no atraso do início da experiência laboral (VINCENS, 1997; ROCHA-DE-OLIVEIRA; PICCININI, 2012a; VOLKMER MARTINS; OLIVEIRA; ROCHA-DE-OLIVEIRA, 2017). Conceitualmente, o termo “inserção profissional” é utilizado pela vertente francesa; enquanto, na literatura anglo-saxônica, a expressão utilizada é transição escolatrabalho (school-to-work).

Diante disso, este ensaio teórico busca: 1) apresentar bases conceituais e ideias centrais da teoria de inserção profissional francesa e da school-to-work; e 2) analisar as contribuições e suas convergências, buscando ampliar e estimular o debate sobre o tema no Brasil, com vistas à criação de uma base teórica que contemple as particularidades 
nacionais e regionais a fim de compreender o processo de transição dos jovens do sistema educacional para a esfera profissional.

\section{A Vertente Francesa de Inserção Profissional}

O termo inserção profissional envolve uma série de definições: transição profissional, entrada na vida ativa, entrada no emprego, transição da escola para o trabalho (VERNIÈRES, 1997; ALVES, 2007). Apesar de portarem uma mesma conceituação, ou seja, a transição do sistema educacional para o sistema laboral, a noção de inserção surgiu no princípio dos anos 1970, quando se verificava, na França, o aumento do desemprego e a ampliação do acesso dos jovens ao sistema de ensino (ROSE, 2018). O termo passou a sobrepor a ideia de entrada na vida ativa, que vigorava na década de 1970, contemplando, predominantemente, o estudo do ingresso no mercado de trabalho das classes menos favorecidas (ROCHA-DE-OLIVEIRA; PICCININI, 2012a).

Rocha-de-Oliveira e Piccinini (2012a) reforçam a importância do estudo sobre essa vertente de inserção com três argumentos: 1) um aspecto de relevância política, em virtude da expansão do contingente juvenil com alta escolarização e dificuldades de inserção no mercado de trabalho. 2) a necessidade de pesquisas teóricas como sustentação dos distintos entendimentos acerca do assunto; e 3) a sucessão de estudos sobre inserção profissional e sua relação com os diferentes estratos sociais e níveis educacionais no país.

Entre as primeiras definições destaca-se a proposta de Vincens (1997), que se baseia na análise do processo de passagem entre as primeiras experiências até a estabilização no mercado de trabalho. De modo similar, Vernières (1997) sustenta que a inserção profissional é o processo em que o indivíduo que jamais ocupou um posto de trabalho encontra uma atividade contínua e remunerada de acordo com sua formação. Nessa perspectiva, a inserção se concluiria com a primeira atividade formal, independentemente de sua relação com o curso.

Rose (2018), ao abordar a trajetória do conceito, aponta que os autores normalmente destacam a ideia de processo buscando a definição dos estágios inicial e final. Assim, podem ser considerados para análise do processo diferentes caminhos, como a probabilidade de sucesso em determinada área; a velocidade que a maioria dos egressos de uma área de formação leva para encontrar uma posição estável; a qualidade da inserção a partir das características dos postos de trabalho encontrados; e os graus de inserção em que a qualidade da inserção se amplia.

Volkmer Martins reforça que a corrente sociológica da inserção profissional a considera "resultante de inúmeras e complexas interações” (2016, p. 69), sendo necessário entendê-la como um processo social ehistórico. Portanto, deve-se analisar seus diferentes contextos de ocorrência (entre países e/ou regiões), considerando-se os sistemas educacionais, bem como as relações de trabalho e industriais dos locais analisados (VOLKMER MARTINS, 2016).

Para Rocha-de-Oliveira e Piccinini, a inserção profissional é

[...] um processo individual, coletivo, histórico e socialmente inscrito. Individual porque diz respeito à experiência vivenciada por cada sujeito na esfera do trabalho, suas escolhas profissionais e expectativas de carreira. É um processo coletivo por ser vivenciado de maneira semelhante por uma mesma geração, ou no interior de grupos profissionais. É histórico, pois se desenvolve ao longo de um período da vida do sujeito, sob a influência de elementos que marcam determinado momento no tempo e no espaço, como políticas públicas, mercado de trabalho, organização do sistema de ensino e políticas de recursos humanos e os pontos de vista "empresariais" sobre as relações entre educação e trabalho. Está inscrito em um dado contexto socioeconômico e cultural, em que, além dos elementos institucionais, há influência das construções e das representações sociais que os indivíduos desenvolvem em relação a essa inserção profissional (2012b, p. 49). 
Dessa forma, o conceito de inserção profissional engloba a análise de aspectos individuais (família, etnia, educação, profissão do pai e da mãe, valores para o trabalho, experiências e expectativas profissionais e técnicas de inserção realizadas), institucionais (leis e regulações sobre as relações de trabalho, políticas de gestão de pessoas e de inserção profissional e concepção de contratos de trabalho de naturezas diversas) e contextuais (estrutura de formação e ocupacional, utilização de tecnologia e situação política, econômica e social do país ou da região) (CORDEIRO, 2002; ROCHA-DE-OLIVEIRA; PICCININI, 2012b).

Rocha-de-Oliveira (2012) contribui ao esquematizar e desdobrar os níveis de análise da inserção profissional (Tabela 1), organizando-os em três eixos: contexto sócio-histórico, aspectos individuais e aspectos institucionais. Para Rocha-de-Oliveira (2012, p. 130) é fundamental que estrutura (vivência/origem dos jovens), biografia ("múltiplas experiências que decorrem da interação em seus contextos sociais") e sua vivência na fase de juventude sejam associadas para a melhor compreensão da inserção profissional.

Tabela 1. Contextos de análise da inserção profissional

\section{Contexto sócio-histórico e aspectos individuais e institucionais da inserção profissional}

Contexto sócio-histórico

Estrutura demográfica e ocupacional Conjuntura econômica

Níveis de formação da mão de obra Desenvolvimento tecnológico e industrial

Origem familiar

Representações do trabalho

Aspectos individuais

Experiências profissionais Expectativas profissionais Estratégias de inserção

Regulamentações estatais Políticas públicas

Aspectos institucionais Políticas de gestão de RH Organizações profissionais Agentes intermediários Instituições de ensino

Fonte: Elaboração própria com base em Rocha-de-Oliveira (2012).

Explorando a discussão sobre o fenômeno, Volkmer Martins (2016) descreve que a inserção profissional dos jovens é composta por três características: o diploma como elemento de distinção social; o ajustamento ao mercado de trabalho (capacitação, condição financeira para a garantia da adaptação e o primeiro emprego) sob responsabilidade de agentes regulamentadores, da família e do próprio jovem; e a ausência de experiências e estabilidade profissional, que empurra o jovem ao desempenho de alguma atividade como comprovação de experiência de trabalho. Nesse contexto, a inserção profissional é considerada um problema social corrente.

Como problema social, não linear e não padronizado, também é simbólico e socialmente estruturado nas vivências "familiar, escolar e relacional", nas quais o intervalo de transição "escola/universidade" e "trabalho/ emprego" é "estruturado por complexos jogos de atores sociais que se estendem em contextos históricos e institucionais determinados” (ROCHA-DE-OLIVEIRA; PICCININI, 2012a, p. 68). Pode-se entender, portanto, que a inserção profissional é um "processo multifacetado, que sofre interferência de aspectos individuais, institucionais e contextuais, e que apreende elementos materiais e simbólicos na relação entre eles" (VOLKMER MARTINS, 2016, p. 81). Nesse sentido, a juventude deve ser compreendida como um "grupo diverso, ou múltiplas juventudes que sofrem influência do contexto histórico em que cresceram” (ROCHA-DE-OLIVEIRA; PICCININI, 2012a, p. 69). Essa multiplicidade de juventudes representa "modos de pensar, de agir e de viver o processo de passagem à vida adulta e que, por consequência, vivem modos distintos de inserção profissional” (ROCHA-DE-OLIVEIRA; PICCININI, 2012a, p. 70). 
Volkmer Martins (2016) expõe que é fundamental aos estudos sobre inserção profissional a compreensão de como ela se relaciona com o déclassement. De acordo com a autora, o termo caracteriza o rebaixamento social, que pode se referir ao

[...] rebaixamento intergeracional (quando os filhos se encontram numa situação menos favorável que os pais), o rebaixamento de diplomados (quando o diploma ocupa uma vaga de emprego inferior à sua qualificação) e o [...] rebaixamento durante o ciclo de vida (quando um acontecimento abrupto provoca uma degradação das condições de vida) (VOLKMER MARTINS, 2016, p. 79).

Peugny ressalta que "os debates sobre o rebaixamento surgem para questionar a posição das classes médias no espaço social, as quais, por sua vez, estariam desestabilizadas” (2014, p. 40). As dificuldades de inserção têm como fundamento a escolarização e a origem social dos indivíduos. Todavia, as trajetórias profissionais de pessoas com oscilações na escolarização (menos escolarizados) aproximam-se das trajetórias daqueles com maiores possibilidades em relação à relevância do diploma para a conquista do emprego. Apesar de o diploma ser considerado um aspecto protetivo contra empregos precários e desemprego, ele "não oferece uma proteção absoluta contra o rebaixamento, mesmo se os mais diplomados são evidentemente aqueles com mais chances de se recolocar na sequência" (PEUGNY, 2014, p. 84). Sobretudo, mesmo que o diploma influa na situação socioprofissional, a origem social da família é tida como um aspecto de alto impacto. Ainda assim, é no momento da colocação profissional que se percebem as situações de rebaixamento, independentemente da origem social do indivíduo (PEUGNY, 2014). Como esquematização dos aspectos abordados pela inserção profissional francesa, apresentamos a Fig. 1, a seguir.

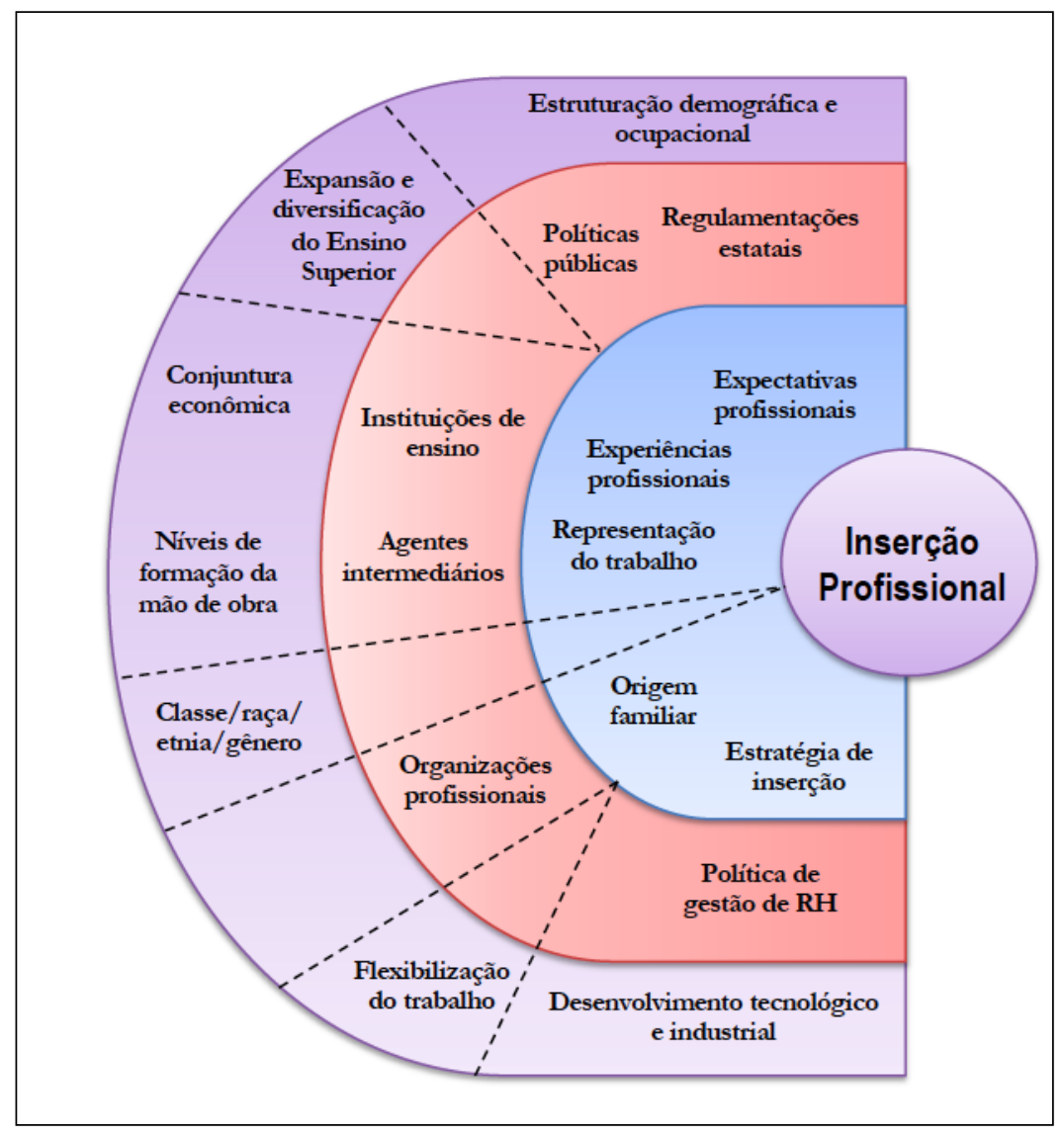

Fonte: Elaboração própria.

Figura 1. Elementos analisados na inserção profissional francesa. 


\section{School-to-work: A Vertente Anglo-saxã de Inserção Profissional}

A transição escola-trabalho representa a compreensão da mudança de um status em um período específico (BRZINSKY-FAY, 2014). De acordo com Ng e Feldman (2007), a etapa de transição escola-trabalho é o principal momento em que os jovens pensam sobre a escolha de carreira. Nessa etapa, reflete-se sobre as habilidades individuais e a qualidade das tomadas de decisão, visto que impactam no sucesso da transição do espaço de estudos para o mercado de trabalho. Conforme Schoon et al. (2001), é nessa etapa que os jovens assumem responsabilidades, tornando-se mais independentes.

A adoção da teoria school-to-work tem sido utilizada em diferentes países, como Austrália (MARKS, 2005), China (LIU et al., 2017), Espanha (ROJAS-GARCÍA, 2013) e Estados Unidos (JOYCE; NOUMARK, 2001). Os estudos realizados indicam pontos em comum: o desenvolvimento de carreira, o planejamento de programas de transição para a esfera do trabalho e a relevância da formação profissional para o sucesso do ingresso na vida laboral.

A school-to-work tem por base a teoria do capital humano (KRUMBOLTZ; WORTHINGTON, 1999). Assim, para o bom resultado da transição school-to-work, os autores elencam dois aspectos: 1) possuir bons antecedentes educacionais amplia as chances para uma colocação profissional mais exitosa; e 2) garantem a competitividade em nível global para as nações que possuem em seu quadro trabalhadores bem-qualificados para a ocupação das vagas.

O desenvolvimento da school-to-work, para Savickas (1999) compõe-se de três etapas: 1) preparação para o ingresso; 2) ingresso; e 3) avaliação do ingresso. A primeira etapa refere-se às decisões de entrada, como a realização de treinamentos e capacitações essenciais para a atividade laboral. Posteriormente, inicia-se o ingresso, no qual o jovem assume a posição de trabalho e toma as medidas de adequação e aprimoramento para sua instalação no posto. Por fim, a etapa de avaliação faz referência à reflexão sobre a posição ocupada e a preferência do indivíduo por ela. Savickas (1999) evidencia que, ao longo desse processo, o jovem faz experimentações e julgamentos até encontrar uma vaga que o satisfaça pessoal e profissionalmente. Todavia, o jovem trabalhador busca a estabilização, entendida como a definição permanente do posto e da carreira a seguir.

Ng e Feldman (2007) afirmam haver diferentes percepções acerca do que é considerada uma transição school-to-work. Para os autores, o school-to-work é retratado sob a perspectiva de efetivação do jovem em um trabalho formal. Contudo, configurações outras de trabalho também estão sendo consideradas para o estudo do school-towork, como trabalho por conta própria e empreendedorismo. Segundo Ng e Feldman (2007), há um impasse entre os pesquisadores do tema, alguns tratando-o por uma ótica objetiva (p. ex., emprego versus desemprego) e outros se utilizando da subjetividade (atitudes, percepções, níveis de estresse etc.). Na visão de Ng e Feldman (2007), o processo de transição abrange a formação da identidade do jovem, da qual diferentes papeis sociais emergem. Para os autores, os indivíduos possuem múltiplas identidades e, por consequência, múltiplos papeis. Assim, para cada ocasião, expectativas sociais são levantadas em relação aos papeis que desempenhamos, algo que é característico nos estágios do ciclo de vida. No âmbito profissional, a construção da identidade do jovem e dos respectivos papeis perpassa um caminho construído por diferentes atores: o próprio jovem, a família e as instituições.

Segundo Masdonati et al. (2016), o processo de school-to-work engloba uma série de fatores psicossociais que influenciam o entendimento dessa transição pelos jovens, elementos esses que abrangem a autoeficácia, o apoio social, a identidade com os papeis sociais e a socialização organizacional. Segundo os autores, um aspecto importante para a análise do school-to-worké o significado dado ao trabalho pelo jovem, pois é reforçadoà medida que o indivíduo percebe a importância de sua atividade para as demais pessoas e o que elas atribuem ao trabalho realizado (p. ex., o papel, a função e os valores que os constituem). Os valores são quesitos expressivos, pois orientam a construção social do indivíduo para o trabalho. Eles devem estar alinhados com as aspirações e os objetivos almejados através do trabalho (MASDONATI et al., 2016).

Lent e Worthington (2000) dedicam-se ao estudo da cultura na transição school-to-work. Para eles, o desenvolvimento da carreira e das demais teorias aplicadas à compreensão do school-to-work pode ser observado pelo enfoque cultural. Para tanto, entre os pontos de discussão, Lent e Worthington (2000) refletem sobre os diversos 
grupos de jovens, principalmente localizados em áreas de risco, deficientes, desfavorecidos economicamente, com limitação de linguagem (idioma), desistentes do ensino secundário, pais adolescentes e jovens homossexuais. Segundo Lent e Worthington (2000), dentro do próprio grupo social, estabelecem-se diferenças culturais, as quais podem influenciar a conduta profissional e as perspectivas de carreiras, como distinções de gênero, classe, processo de aculturação e rede de influências. Por isso, os autores argumentam que se deve estar atento a essas variações.

Vários trabalhos destacam as mudanças no processo de transição ao longo do tempo. Se antes os jovens detinham o controle do seu futuro profissional, podendo fazer previsões e formular ideias sobre melhores escolhas, atualmente têm de agir sob um cenário de incertezas e resultados imprevisíveis, algo que vem modificando as estratégias de colocação no mercado dos trabalhadores em formação. A transição escola-trabalho atravessa diferentes situações, sendo marcada pela ocupação de curtos e precários postos de trabalho até o encontro de um emprego estável (MASDONATI et al., 2016).

As desigualdades sociais entre jovens continuam estendendo-se às transições para o mercado de trabalho. Apesar de esses jovens alcançarem determinada qualificação, que lhes possibilite um ingresso profissional menos inseguro, as condições estruturais ainda os impedem de competir em mesmo nível que os demais jovens provindos de uma origem social mais favorável. Como exemplificam Schoon et al. (2001), as desigualdades sociais associadas à classe percorrem as desigualdades de gênero, de preenchimento dos postos de trabalho e de abandono dos estudos. A fragilidade dos mecanismos de inserção profissional impacta, em longo prazo, as estratégias para amenizar o ingresso do jovem no trabalho, o que, por um lado, dificulta os esforços de manutenção das ofertas de emprego e as ações de preservação do capital humano e, por outro, interfere na constituição de carreiras e reforça a desigualdade social. Casos de exclusão de grupos minoritários, como imigrantes e jovens de baixas renda e educação, apontam a segmentação de oportunidades existente no mercado de trabalho. Como representação da inserção school-to-work, apresentamos a Fig. 2, a seguir.

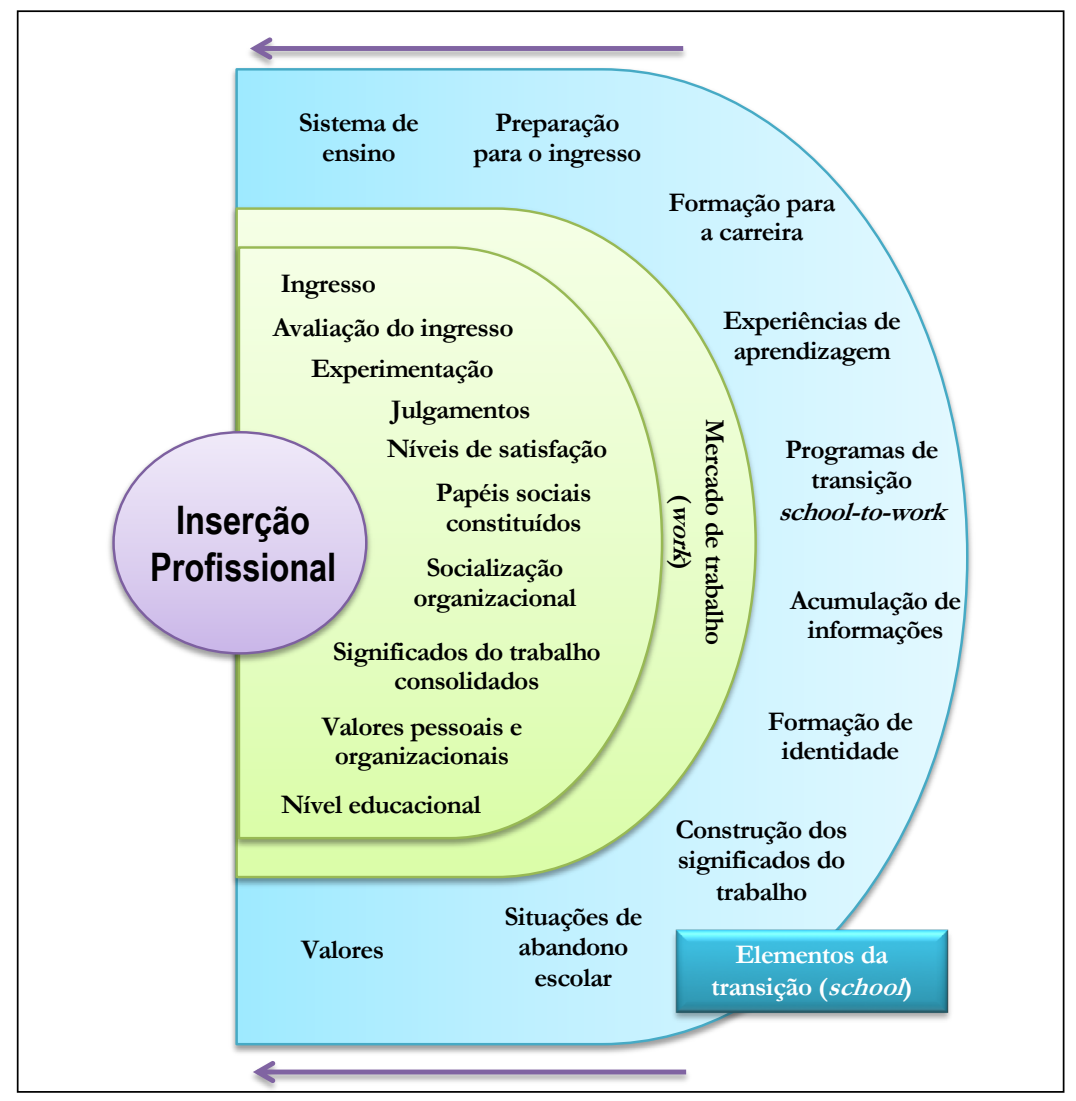

Fonte: Elaboração própria.

Figura 2. Elementos analisados na transição school-to-work. 


\section{Aproximando a Discussão}

A entrada dos jovens no mercado de trabalho é um tema amplo e passível de ser analisado sob diferentes óticas. Na base conceitual francesa, destaca-se a importância dos elementos do contexto no período de ingresso do jovem no mercado. No modelo school-to-work, o foco maior está na ação individual como responsável pelo sucesso de sua inserção, apesar de conter um aparato institucional orientado a programas de preparação para o ingresso profissional e a constituição de carreira.

$\mathrm{Na}$ abordagem francesa, a inserção é um "processo"; no school-to-work, uma "mudança de status". Ou seja, pela abordagem francesa, pode-se compreender essa transição como algo que ocorre ao longo da vida do trabalhador, com entradas e saídas (emprego e desemprego), ou como algo definido no tempo, uma fase/etapa na vida do indivíduo, definida como a transição do sistema de formação para o trabalho.

Aqui, aponta-se a viabilidade de integração dos elementos de ambos os modelos, sem deixar de considerar diferenças teóricas e estruturais pertinentes a cada um. Primeiramente, merece destaque que os dois partam de uma preocupação sócio-histórica semelhante: as mudanças socioeconômicas dos anos 1970 e a consequente desestruturação do mercado laboral, com a redução de postos de trabalho qualificados e o crescimento do desemprego, o qual teve impacto expressivo no processo de início da vida ativa dos jovens.

$\mathrm{Na}$ análise das duas propostas, alguns pontos se destacam para uma discussão integrada: aspectos de convergência, rebaixamento de diplomas como um risco presente, particularidades dos caminhos de inserção e importância das instituições de educação superior.

\section{Caminhos de Convergência}

Acredita-se que, ao explorar a convergência entre as propostas, é possível dar maiores abrangência e profundidade à discussão sobre a passagem da escola/Ensino Superior ao mercado de trabalho. Como integração do modelo, percebem-se: o ambiente sócio-histórico moldando os traços de uma população (demografia, economia, desenvolvimento tecnológico, novas formas de trabalho, nível de formação e expansão do ensino) e a realidade de seus membros em substratos sociais diferenciados, perpassando questões de classe, gênero e raça (aspectos que acompanham o trabalhador em toda a sua inserção); a composição individual do trabalhador (expectativas e experiências laborais, representatividade do trabalho); os fatores institucionais, como as políticas de Recursos Humanos; os agentes intermediários; as regulamentações estatais; e as organizações profissionais.

Como pontos-chave da integração dos modelos, aponta-se a representatividade das instituições de ensino e das políticas públicas, consideradas aspectos institucionais na inserção francesa. No school-to-work, o sistema de ensino é o ambiente de análise e preparação para o ingresso do jovem no mercado de trabalho, estando as políticas públicas inseridas nesse cenário como caminhos para a formação (cidadã e profissional) dessa juventude. Assim, eleva-se a importância das instituições de ensino e das políticas públicas no modelo francês de inserção. Além de participarem do eixo institucional, tais políticas sobressaem como dispositivos de staff, juntamente com as agências de intermediação, por exemplo as empresas de terceirização e consultorias de recrutamento e seleção.

Nesse sentido, instituições de ensino, políticas públicas e agências de intermediação assumem uma posição especial entre os aspectos institucionais e, por consequência, passam a receber maior atenção em sua organização interna, de forma a repensar os papeis que ocupam e a sua importância para a inserção profissional. 


\section{Déclassement ou Rebaixamento}

Em ambas as teorias de inserção, francesa e school-to-work, a situação do rebaixamento profissional (e, por consequência, social) é levada em consideração. Contudo, o que particulariza esses modelos de inserção é a forma como tratam esse problema.

$\mathrm{Na}$ inserção profissional francesa, a questão do rebaixamento do diploma surge em decorrência do cenário de alterações das formas de emprego, quando se percebem diversificação de vínculos contratuais e maior acirramento da disputa entre candidatos no preenchimento das vagas disponíveis, sendo sua ocupação dependente do atendimento aos requisitos necessários, principalmente em relação ao nível de qualificação. Nesse cenário, há a redução dos postos de trabalho por tempo indeterminado e cresce o contingente de jovens trabalhadores com maior qualificação, tornando a ocupação dos postos cada vez mais complexa. O mercado de trabalho deixa claro que o acesso às vagas não é para todos, principalmente para aqueles com maior tempo de estudo. Para eles, cabe o preenchimento de cargos que demandam capacitações inferiores às que possuem. Ou seja, o rebaixamento de diplomas é um fenômeno do mercado de trabalho que acompanha a dinâmica social e ocorre proporcionalmente às particularidades socioeconômica e à histórica dos indivíduos.

Portanto, o rebaixamento (déclassement), pela vertente francesa, engloba os aspectos contextuais e busca entender o fenômeno a partir deles. O caminho percorrido pelo jovem trabalhador é marcado por condições tanto ambientais, quanto sociais, econômicas, históricas, organizacionais - políticas e práticas empresariais, legislação trabalhista etc. - e individuais - herança familiar, ciclo de vida, escolaridade etc. Diante disso, depreende-se que o modelo francês de inserção olha para o cenário no qual o trabalhador está inserido. Nesse sentido, o rebaixamento não é resultante apenas da ação do indivíduo, mas é também influenciado pelo movimento do mercado de trabalho.

No modelo school-to-work, a forma de enfrentamento ao rebaixamento do diploma deve ser antecipada, para que medidas de precaução sejam empreendidas. Isto é, desde que os sintomas do desemprego decorrente das transformações socioeconômicas foram percebidos, ações estruturais e de reorganização do espaço de trabalho foram desenhadas em uma parceria dos governos com entes privados como estratégia de atuar sobre essa problemática, o que tomou força a partir da década de 1970 em países europeus e nos Estados Unidos - período de crise no emprego e no ensino. Diante disso, programas de qualificação e preparação para o ingresso no trabalho para a população de estudantes desses países foram projetados. Basicamente, os programas de school-to-work são elaborados tendo como base a noção de formação para a carreira. Por isso, quando o jovem ingressa no sistema de ensino, inicia um processo de preparação para a inserção no mercado de trabalho, impactando, por consequência, a concepção do ensino, voltada para a aprendizagem profissional.

\section{Particularidades Nacionais e Individuais de Inserção Profissional}

A análise das duas correntes de estudos da transição do jovem do sistema de formação permite compreender particularidades do caminho de ingresso em cada país. Na vertente francesa, a preocupação central voltou-se para a reunião de pesquisadores de diferentes áreas, de modo a ampliar a compreensão sobre o fenômeno e a sistematização de informações por meio de surveys periódicos, realizados pelo Cereq (VOLKMER MARTINS, 2016). Esse acompanhamento periódico da situação dos ingressantes no mercado de trabalho serve de sustentação para o planejamento e a execução de políticas públicas nacionais e regionais, bem como é utilizado no processo de orientação dos jovens sobre as perspectivas profissionais de cada área. 
$\mathrm{Na}$ abordagem school-to-work, nota-se a centralidade na trajetória individual - com grande atenção aos processos de escolha e ingresso no mercado de trabalho e enfoque nos direcionamentos de cada um no momento do ingresso. Embora reconheça a ação dos elementos contextuais, o foco maior recai sobre a conduta individual. Os estudos dessa vertente buscam formas de potencializar a "escolha certa", tornando o processo de ingresso no mercado de trabalho uma responsabilidade mais centrada no indivíduo.

Seja do ponto de vista do contexto, seja das trajetórias de cada pessoa, destaca-se como central, na discussão sobre inserção profissional, a existência de particularidades do processo. Essas especificidades podem estar em um limite extremo ligado ao contexto nacional, compreendendo a inserção como processo coletivo (ROCHA-DE-OLIVEIRA, 2012) ligado a aspectos estruturais, por exemplo a estrutura ocupacional e de formação de cada país ou região e impactos de alterações do cenário econômico e social desses locais. No entanto, há sempre que se observar os limites da possibilidade da compreensão dessa coletividade, pois, embora situados numa mesma região ou país, também haverá diferenças (classe, gênero, raça entre outras) dentro dos grupos juvenis e particularidades do processo de inserção profissional em cada área de formação.

No outro extremo, a inserção é um processo individual, com experiências e peculiaridades vivenciadas de modo único na trajetória de vida de cada sujeito. Embora única para cada pessoa, haverá semelhança com outros jovens de formação e condições econômicas e sociais semelhantes. Assim, a análise profunda de especificidades de trajetórias individuais pode contribuir para entender o processo de inserção de grupos específicos, sempre tomando o cuidado de não assumir um aspecto prescritivo de um "caminho para o sucesso".

\section{Ação das Instituições de Ensino}

Kogan e Unt (2005) atentam para o papel do sistema educacional na passagem do jovem para o mercado de trabalho. Para os autores, a responsabilidade sobre o ingresso na vida profissional não depende apenas do jovem, pois ele está envolto por uma infraestrutura maior e capaz de fornecer subsídios essenciais para a sua transição. Joyce e Noumark (2001) evidenciam a estrutura de ensino aplicada em programas de school-to-work nos Estados Unidos: o aprendizado escolar baseado em experiências, desenvolvimento de habilidades e identificação de carreiras; o aprendizado baseado no trabalho, com treinamentos, experiências no próprio local de trabalho, harmonização entre currículo escolar e interesses de carreira; e a conexão entre atividades escolares e profissionais, formando parcerias com empresas locais.

Pela perspectiva francesa, a inserção profissional é entendida como um processo com múltiplas dimensões, que podem definir a forma de inserção de um determinado público e possibilitar, sobretudo, a comparação de públicos distintos. Dessa forma, as instituições de ensino compõem um entre outros pontos que merecem atenção. Como afirmado na literatura, busca-se o trabalho conjunto das organizações com o sistema de ensino como estratégia de alavancagem das possibilidades de sucesso no mercado. O sistema de ensino como provedor de educação e preparador para o trabalho acumula questionamentos. A massificação do ensino ao longo dos tempos levantou dúvidas quanto à qualidade do ensino ofertado, em virtude da proliferação de instituições de menores reconhecimento e credibilidade. Por outro lado, o modelo schoolto-work está concentrado na passagem do sistema de ensino para o mercado de trabalho. Logo, é naquele ambiente que se traçam as estratégias de inserção profissional do jovem ou acadêmico. Nesse modelo, o sistema de educação é protagonista e tanto o Estado quanto as organizações privadas se responsabilizam pelo êxito da transição. Aqui, a inserção profissional é entendida como uma troca de status: a passagem da escola/ universidade (como um ambiente de formação acadêmico-profissional) para o mercado (a disposição de um profissional pronto e com concepção de carreira constituída). 
Assim, programas de formação profissional e de carreira, tanto públicos quanto privados, fazem-se presentes; a educação assume uma base de cunho profissional e busca-se alinhar o ensino às noções de trabalho - vivências profissionais em organizações. No school-to-work, as instituições de ensino, além de educar, trabalham na conscientização para o trabalho, empenhando-se na construção de valores e sentidos para o trabalho, bem como na constituição de papeis sociais e de uma identidade; também promovem experiências de aprendizagem e formação para a carreira; e atuam em questões delicadas, como o abandono escolar - mais precisamente em casos de indivíduos marginalizados ou periféricos, em situação de crise familiar ou não (com envolvimento da família no processo). Todas as iniciativas integram um plano de preparação para o ingresso profissional.

É importante salientar que o school-to-work é um programa de concepção governamental e vem se desenvolvendo desde a década de 1970, com forte expressão nos anos 1990. É um modelo orientado para a inserção expressivo, em países europeus e nos Estados Unidos. No Brasil, as universidades, nos últimos anos, vêm oferecendo serviços de aconselhamento profissional aos seus estudantes, algo que se aproxima de uma orientação para carreira ou orientação vocacional; contudo, não são todas capazes de agregar essa prática ao seu conjunto de serviços educacionais. Portanto, as instituições brasileiras permanecem em estágio inicial, com iniciativas pulverizadas, algo que se diferencia da mentalidade do school-to-work: observa-se o funcionamento de uma rede de colaboração público-privada subsidiada por um plano unificado de atuação, voltado a solidificação, preparação e fortalecimento da força de trabalho futura.

\section{Considerações Finais: Pensando uma Proposta para o Brasil}

Este trabalho teve por objetivo apresentar e aproximar as teorias de inserção profissional francesa e school-to-work. Após a apresentação das bases teóricas de cada teoria, buscou-se explorar aspectos de convergência das duas correntes teóricas. Espera-se que esta discussão possa ampliar e estimular o debate sobre o tema no Brasil, com vistas à criação de uma base teórica que contemple as particularidades nacionais e regionais para compreender o processo de transição escola/Ensino Superior para o ambiente profissional. Assim, destacam-se quatro pontos.

Primeiramente, depois de décadas de concentração da formação superior nas classes mais altas, o Brasil passou por um expressivo aumento do acesso ao nível superior, nos últimos 15 anos, fazendo com que aumentasse significativamente a oferta de jovens diplomados, condição estrutural que alterou o processo de inserção profissional no Brasil. Essa expansão, que criou e ampliou modalidades de cursos antes não tradicionais - tecnólogos e ensino a distância, por exemplo - levou a uma reorganização e a nova estratificação do sistema de ensino, além de ter alterado o processo de inserção profissional existente.

Em segundo lugar, novos grupos juvenis passam a ter acesso ao Ensino Superior em função de políticas, como as cotas socioeconômicas e raciais nas universidades públicas e a ampliação do Prouni. Assim, jovens oriundos de classes sociais mais populares têm mais facilidade de acesso ao Ensino Superior e talvez tenham melhorado suas condições de inserção. No entanto, ainda há dúvida quanto à efetividade dessa contribuição, pois apenas a qualificação não se mostrou solução para melhores condições no mercado de trabalho, segundo dados dos Estados Unidos e da Europa.

Em terceiro lugar, a ampliação do número de diplomados amplia o risco de rebaixamento de diplomas, fato que se agrava pela estratificação criada para os cursos de nível superior e as expectativas dos jovens, em especial de classes populares, que, embora tenham acesso, são os primeiros de suas famílias a ter curso superior e, muitas vezes, não têm acesso à mesma rede e orientações para o ingresso no mercado de 
trabalho daqueles de classes mais altas. Há o risco de que jovens de classes populares passem a ocupar um mercado de trabalho secundário, em condições precárias de trabalho e inseguranças no emprego. Enquanto isso, mesmo havendo um rebaixamento para os trabalhadores de classe social mais elevada, eles ainda permanecem ocupando postos de trabalho mais qualificados, pois, considerando a visão contextual, o meio age sobre a inserção do indivíduo.

Em quarto lugar, o papel das instituições de Ensino Superior se altera nesse processo, mas ainda se nota muita dificuldade para adequação à nova realidade. $\mathrm{O}$ antigo modelo universitário, no qual predominavam distância do mercado de trabalho e falta de orientação e preparação dos jovens para ingressar na vida laboral, ainda é preponderante.

Por fim, ressalta-se que este trabalho não intenta esgotar as discussões e as possibilidades de reflexão sobre o tema, mas mostrar bases teóricas que permitam contribuir para aprofundar a discussão sobre a inserção profissional juvenil no Brasil e dialogar sobre elas.

\section{Contribuições dos Autores}

Problematização e Conceitualização: Moraes JP e Rocha-de-Oliveira S; Metodologia: Moraes JP e Rocha-de-Oliveira S; Análise: Moraes JP e Rocha-de-Oliveira S; Redação: Moraes JP e Rocha-de-Oliveira S.

\section{Referências}

ALVES, N. Inserção profissional dos jovens: do problema social ao objecto sociológico. Lisboa: Unidade de I\&D de Ciências da Educação, 2007. Disponível em: https://repositorio.ul.pt/bitstream/10451/3162/30/ ulsd054512_7_Cap_2.pdf. Acesso em: ago. 2017.

BRZINSKY-FAY, C. The measurement of school-to-work transitions as processes: about events and sequences. European Societies, London, v. 16, n. 2, p. 213-232, 2014. https://doi.org/10.1080/14616696.2013.821620

CORDEIRO, J. P. Modalidades de inserção profissional dos quadros superiores nas empresas. Sociologia, Problemas e Práticas, Lisboa, n. 38, p. 79-98, 2002.

GUIMARÃES, N. A. Empresariando o trabalho: os agentes econômicos da intermediação de empregos, esses ilustres desconhecidos. Dados, Rio de Janeiro, 2008, v. 51, n. 2, p. 275- 311. https://doi.org/10.1590/ S0011-52582008000200003

INEP [INSTITUTO NACIONAL DE ESTUDOS E PESQUISAS EDUCACIONAIS ANÍSIO TEIXEIRA]. Sinopses Estatísticas da Educação Superior 2018. Brasília, DF: Inep, 2019.

JOYCE, M.; NOUMARK, D. School-to-work programs: information from two surveys. Monthly Labor Review, Washington, v. 124, p. 38, 2001.

KOGAN, I.; UNT, M. Transition from school to work in transition economies. Europe Societies, London, v. 7, n. 2, p. 219-253, 2005. https://doi.org/10.1080/14616690500083428

KRUMBOLTZ, J. D.; WORTHINGTON, R. L. The school-to-work transition from a learning theory perspective. The Career Development Quarterly, Alexandria, v. 47, n. 4, p. 312-325, 1999. https://doi. 
org/10.1002/j.2161-0045.1999.tb00740.x

LENT, R. W.; WORTHINGTON, R. L. On school-to-work transition, career development theories, and cultural validity. The Career Development Quarterly, Alexandria, v. 48, n. 4, p. 376-384, 2000. https://doi. org/10.1002/j.2161-0045.2000.tb00883.x

LIU, Y. et al. From school to university to work: migration of highly educated youths in China. The Annals of Regional Science, Berlin, v. 59, n. 3, p. 651-676, 2017. https://doi.org/10.1007/s00168-016-0753-X

MARKS, G. N. Issues in the school-to-work transition: evidence from the longitudinal surveys of Australian youth. Journal of Sociology, London, v. 41, n. 4, p. 363-385, 2005. https://doi.org/10.1177/1440783305058470

MASDONATI, J. et al. The evolution of work values during the school-to-work transition: the case of young adults in the 'missing middle.' International Journal for Educational and Vocational Guidance, Dordrecht, v. 16, n. 2, p. 189-212, 2016. https://doi.org/10.1007/s10775-015-9300-z

NG, T. W. H.; FELDMAN, D. C. The school-to-work transition: A role identity perspective. Journal of Vocational Behavior, Amsterdam, v. 71, n. 1, p. 114-134, 2007. https://doi.org/10.1016/j.jvb.2007.04.004

OCDE [ORGANISATION DE COOPERATION ET DE DEVELOPPEMENT ÉCONOMIQUES]. Education at a glance 2018: Indicadores da OCDE. Paris: OCDE, 2018.

PEUGNY, C. O destino vem do berço? Desigualdades e reprodução social. Campinas: Papirus, 2014.

ROCHA-DE-OLIVEIRA, S. Inserção profissional: perspectivas teóricas e agenda de pesquisa. Revista Pensamento Contemporâneo em Administração, Rio de Janeiro, v. 6, n. 1, p. 124-135, jan./mar. 2012. https://doi.org/10.12712/rpca.v6i1.124

ROCHA-DE-OLIVEIRA, S.; PICCININI, V. C. Contribuições das abordagens francesas para o estudo da inserção profissional. Revista Brasileira de Orientação Profissional, Campinas, v. 13, n. 1, p. 63-73, jan./jun. 2012a.

ROCHA-DE-OLIVEIRA, S.; PICCININI, V. C. Uma análise sobre a inserção profissional de estudantes de administração no Brasil. Revista de Administração Mackenzie, São Paulo, v. 13, n. 2, p. 44-75, mar./abr. 2012b. https://doi.org/10.1590/S1678-69712012000200003

ROJAS-GARCÍA, G. Transitioning from school to work as a Mexican 1.5 er: upward mobility and glass-ceiling assimilation among college students in California. The ANNALS of the American Academy of Political and Social Science, Thousand Oaks, v. 648, n. 1, p. 87-101, 2013. https://doi.org/10.1177/0002716213482434

ROSE, J. L'insertion professionnelle : une notion discutée mais robuste. In : COUPPIE, T. et al. 20 ans d'insertion professionnelle des jeunes : entre permanences et évolutions. Marseille : Cereq, 2018.

SANTOS, G. P. G. Juventudes, trabalho e educação: uma agenda pública recente e necessária. Por quê? In: MACAMBIRA, J.; ANDRADE, F. R. B. (orgs.). Trabalho e formação profissional: juventudes em transição. Fortaleza: IDT/UECE/BNB, 2013, p. 37-55.

SAVICKAS, M. L. The transition from school to work: a developmental perspective. The Career Development Quarterly, Alexandria, v. 47, n. 4, p. 326-336, 1999.

SCHOON, I. et al. Transitions from school to work in a changing social context. Young, London, v. 9, n. 1, p. 4-22, 2001. https://doi.org/10.1177/110330880100900102 
VERNIÈRES, M. L’insertion professionnelle, analyses et debats. Paris : Economica, 1997.

VINCENS, J. L'insertion professionnelle des jeunes : à la recherche d'une definition conventionnelle. Formation et emploi, Mont-Saint-Aignan, n. 60, p. 21-36, oct./dec. 1997.

VOLKMER MARTINS, B. Expansão e diversificação do Ensino Superior no Brasil: a mobilidade social e a inserção profissional dos jovens estudantes e egressos de cursos superiores da região metropolitana de Porto Alegre/RS. 2016. Tese (Doutorado em Administração) - Escola de Administração, Universidade Federal do Rio Grande do Sul, Porto Alegre, 2016.

VOLKMER MARTINS, B.; OLIVEIRA, L. B.; ROCHA-DE-OLIVEIRA, S. Rebaixamento de diplomas de jovens estudantes e egressos do ensino superior: proposta de escala de mensuração. XLI Encontro da ANPAD. São Paulo, São Paulo, 2017.

VOLKMER MARTINS, B.; ROCHA-DE-OLIVEIRA, S. Reflexões sobre a empregabilidade dos jovens provenientes de cursos superiores de tecnologia. Revista Pensamento Contemporâneo em Administração, Rio de Janeiro, v. 11, n. 1, p. 37-54, 2017a. https://doi.org/10.12712/rpca.v11i1.80

VOLKMER MARTINS, B.; ROCHA-DE-OLIVEIRA, S. Expansão e diversificação do ensino superior, impactos no mercado de trabalho e inserção profissional no Brasil: reflexões iniciais e proposta de agenda de pesquisa. Desenvolve - Revista de Gestão do Unilasalle, Canoas, v. 6, p. 53, 2017b. https:// doi.org/10.18316/ desenv.v6i2.3196

\section{Sobre os Autores}

Jhony Pereira Moraes é doutorando e Mestre em Administração (área de Gestão de Pessoas e Relações de Trabalho) pela UFRGS (PPGA/UFRGS). Graduado em Administração pela UniRitter. É professor da Faculdade de Desenvolvimento do Rio Grande do Sul e da Faculdade SEG. Atua como docente em nível de pós-graduação. Tem interesse nos seguintes temas de pesquisa: carreira; inserção profissional (francesa e school-to-work); ensino-aprendizagem em Administração; gestão da diversidade nas organizações; gestão de pessoas; e relações de trabalho.

Sidinei RochA-DE-Oliveira é doutor em Administração pela Université Pierre Mendès-France - Grenoble 2 em cotutela com a Universidade Federal do Rio Grande do Sul (UFGRS). Tem graduação (2002) e mestrado (2004) em Administração pela UFRGS. Professor Associado no curso de Administração da UFRGS. Coordenador do Programa de Pós-graduação em Administração (2019 e 2021). Tem interesse de pesquisa nas áreas de: mercado de trabalho; inserção profissional e o processo de mobilidade social; e as interseccionalidades de classe, gênero e raca na construção das carreiras contemporâneas.

Recebido: 10 maio 2019 